\title{
Pharmacotherapeutic audit meetings as a tool of improving prescribing practices
}

\author{
Vinod Kumar' ${ }^{1}$, Ravi Kant ${ }^{2}$, Shailendra Handu ${ }^{3}$, Jaya Charturvedi ${ }^{4}$, \\ Ajeet Singh Bhadoria ${ }^{5}$, Puneet Dhamija ${ }^{3 *}$
}

\begin{abstract}
${ }^{1}$ Department of Pharmacology, All India Institute of Medical Sciences, Rishikesh, Uttarakhand, India ${ }^{2}$ Director and CEO, All India Institute of Medical Sciences, Rishikesh, Uttarakhand, India

${ }^{3}$ Department of Pharmacology, All India Institute of Medical Sciences, Rishikesh, Uttarakhand, India ${ }^{4}$ Department of Obstetrics and Gynaecology, All India Institute of Medical Sciences, Rishikesh, Uttarakhand, India ${ }^{5}$ Department of Community and family Medicine, All India Institute of Medical Sciences, Rishikesh, Uttarakhand, India
\end{abstract}

Received: 17 August 2020

Accepted: 11 September 2020

\author{
*Correspondence: \\ Dr. Puneet Dhamija, \\ Email: drpdhamija@gmail.com
}

Copyright: $@$ the author(s), publisher and licensee Medip Academy. This is an open-access article distributed under the terms of the Creative Commons Attribution Non-Commercial License, which permits unrestricted non-commercial use, distribution, and reproduction in any medium, provided the original work is properly cited.

\begin{abstract}
Background: Pharmacotherapeutic audit meeting (PTAM) is a good tool to review prescriptions for rationality and suggest measures for improving quality of prescriptions. To promote this, World Health Organization (WHO) and International Network for Rational Use of Drugs (INRUD) provided drug prescribing and drug use indicators. To assess the impact of PTAMs as an intervention for improving quality and rationality of prescriptions.

Methods: This was a single centre, prospective study conducted from December 2018-February 2020. Prescriptions from outpatient surgical departments were collected, screened using WHO/INRUD core indicators and discussed in PTAMs. The same process was repeated over next 2 months to assess change in prescribing patterns after PTAM. Chisquare and Student's t-test was used for statistical analysis.

Results: The difference in proportions for antibiotic prescribing was $8.7 \%$ [95\% CI $(1.0 \%-16.7 \%)$, $\mathrm{p}=0.02]$; injectable preparation use was $0.7 \%$ [95\% CI $(-0.4 \%-2.3 \%) \mathrm{p}=0.23$ ]; prescriptions with generic name drugs was $10.9 \%$ [95\% CI $(5.6-16.2 \%) \mathrm{p}<0.0001]$ and prescriptions from Essential drug list (EDL) was 8.1\% [95\% CI $(2.5 \%-13.5 \%) \mathrm{p}=0.0046]$.

Conclusions: Our research showed PTAM could be an effective tool to implement WHO/INRUD drug prescribing indicators robustly. Hence, it could be included in WHO/INRUD policies as an intricate part of institutional healthcare delivery system.
\end{abstract}

Keywords: Essential drug list, Generic name, Pharmacotherapeutic audit meeting, Rationality, WHO/INRUD drug prescribing indicators

\section{INTRODUCTION}

Rational drug prescription is a practice when an appropriate drug with correct dosage, formulation, frequency and duration is prescribed. Also, it should be affordable and effective. A prescription is an important instructive document from prescriber to a dispenser which should be precise, complete and tidy. It is indeed a basic necessity for a doctor to learn and follow rational prescription writing. It has been astonishingly seen that worldwide, about $50 \%$ of drugs prescribed were wrong and another $50 \%$ of patient group prescribed correctly, had been consuming a wrong drug. ${ }^{1}$ To promote rational prescribing, World Health Organization (WHO) and 
International network for rational use of drugs (INRUD) jointly provided a few drug prescribing and drug use indicators. $^{2}$ These indicators help to understand prescription pattern, errors in prescriptions and to find out various ways to rectify them.

Prescription audit is a continuous cycle, involving observing practice, setting standards, comparing practice with standards, implementing changes and observing new practice. Quality of medical care rendered can only be assessed by prescription audit, because it is based on documented evidence to support diagnosis and treatment. Hence, prescription audit is a tool and its application is science. $^{3}$

Pharmacotherapeutic audit meetings (PTAM) are defined as a series of regular meetings between administrators, representatives of clinical departments, clinical pharmacologist and microbiologist during which information and views about pharmacotherapy for a particular patient or group are exchanged with an aim to improve drug prescribing practices. Continuing educational activities are an integral part of PTAM where information about rational use of drugs, recent advances in management of disease conditions are discussed. PTAM is a combination of prescription audit and educational activity with an aim to generate rational prescriptions.

In light of above facts, we had planned this study to assess the impact of PTAM on promoting rationality and quality of prescription writing. The prime aim of this study was to minimize common prescription errors, and hence promote improved patient care.

\section{METHODS}

This was a cross-sectional, prospective study conducted over a period of 14 months (December 2018-February 2020) on prescriptions from outpatient clinics of Orthopedics, General Surgery, Obstetrics and Gynecology (OBG), Otorhinolaryngology (ENT) and Urology. Clearance was obtained from Institutional Ethics Committee and waiver of consent was granted to conduct the study. Investigator collected prescriptions of selected departments from retail pharmacy within hospital premises. Data from prescriptions was anonymized and extracted on a customized case record form designed specifically for this study.

Data regarding demographic details, provisional/definitive diagnosis, pharmacotherapy and parameters required as per WHO Core indicators was extracted. All prescriptions were analysed for calculating WHO Core prescribing indicators and Indices of rational drug prescribing (IRDP) developed by Zhang and Zhi. ${ }^{4}$ For calculation of average number of drugs prescribed, rational antibiotic and injection safety indices, following formula was used:

$$
\text { Index }=\text { optiml value } \div \text { observed value }
$$

All other indices (index of generic name, index of Essential drugs list (EDL)) were calculated by the following formula:

$$
\text { Index }=\text { observed value } \div \text { optimal value }
$$

The optimal index for all indicators were: Values closer to 1 indicated rational drug use and vice versa. Index of rational drug prescribing (IRDP) was calculated for all prescriptions by adding the index values of all prescribing indicators. All prescriptions not following good prescribing practice were reserved for discussion in PTAM. Additionally, prescriptions with some specific issues were also reserved for discussion in PTAMs.

Peer-review of prescriptions was done by a balanced group of specialists, thereby ascertaining rationality by reduced bias. Experts from pre-clinical and para-clinical departments provided neutral inputs on prescriptions from clinical departments. Administrators were able to understand practical issues and modify the processes as required. This process was repeated again to assess impact of meeting on drug prescribing practices.

All data collected was expressed as percentage in tables. Chi-square test was used to compare categorical data, and Student's t-test was used for continuous variables. Significance of results was expressed as $\mathrm{p}$ value of $<0.05$ for each parameter with $95 \%$ Confidence interval (CI). Data analysis was done using Microsoft excel 2016 and Statistical package for social sciences (SPSS) 22.

\section{RESULTS}

In this study, total 521 prescriptions from five surgical departments were screened over a period of 14 months. A total of 180 and 341 prescriptions were screened for 1 st and 2nd PTAM respectively.

The mean age of patients in 1stand 2nd PTAM was $40.8 \pm 8.90$ and $42.1 \pm 8.84$ years respectively. The patients analysed in both PTAMs were comparable in terms of gender distribution. $48.9 \%$ patients were males, while $51.1 \%$ were females. Our study showed the effect of intervention (PTAM) on the prescription writing practices in terms of WHO core prescribing parameters. The average number of drugs prescribed per encounter was similar in all the departments, data being represented in figure 1 . Average drug prescribed was 2.2 (1-6) in 1st PTAM and $2.3(1-5)$ in 2nd PTAM. (Figure 1)

A statistically non-significant improvement in prescription writing practice of generic name was seen in department of OBG $(p=0.29)$ and urology $(p=0.82)$. (Figure 2) As far as drugs prescribed from National list of essential medicine (NLEM) was concerned, a decline was noted after 1st PTAM, which was not statistically significant each for departments of orthopaedics $(\mathrm{p}=0.46)$; obstetrics and gynaecology $(\mathrm{p}=0.59)$; general surgery $(\mathrm{p}=0.06)$ and urology $(\mathrm{p}=0.26)$. While a significant decline was noted for 
department of ENT solely ( $\mathrm{p}=0.02)$. It was also observed that no significant change occurred for the use of injectable preparations after 1 st PTAM. Some variations were observed in each department, but the change was not statistically significant ( $\mathrm{p}>0.05)$.

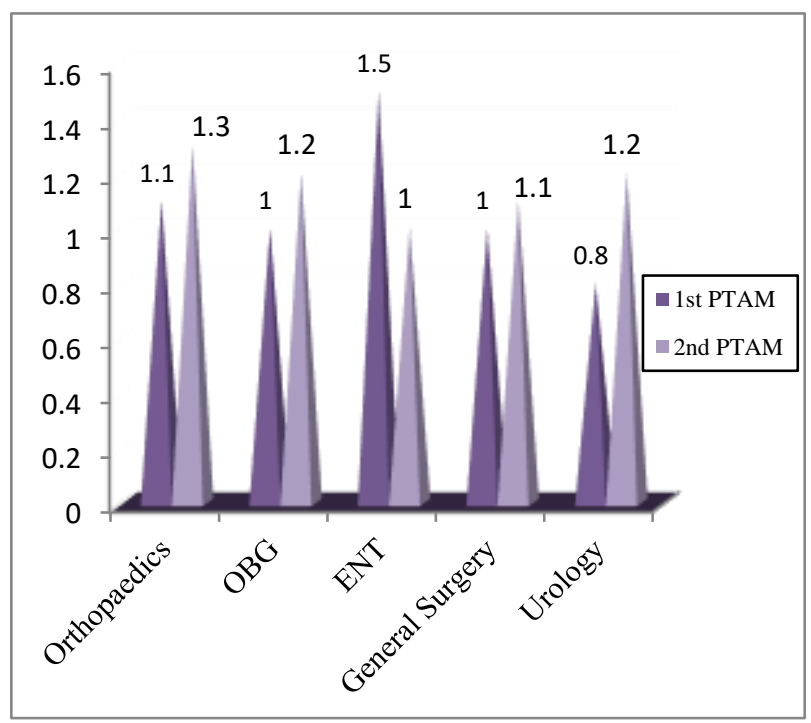

Figure 1: Average number of drugs prescribed per encounter.

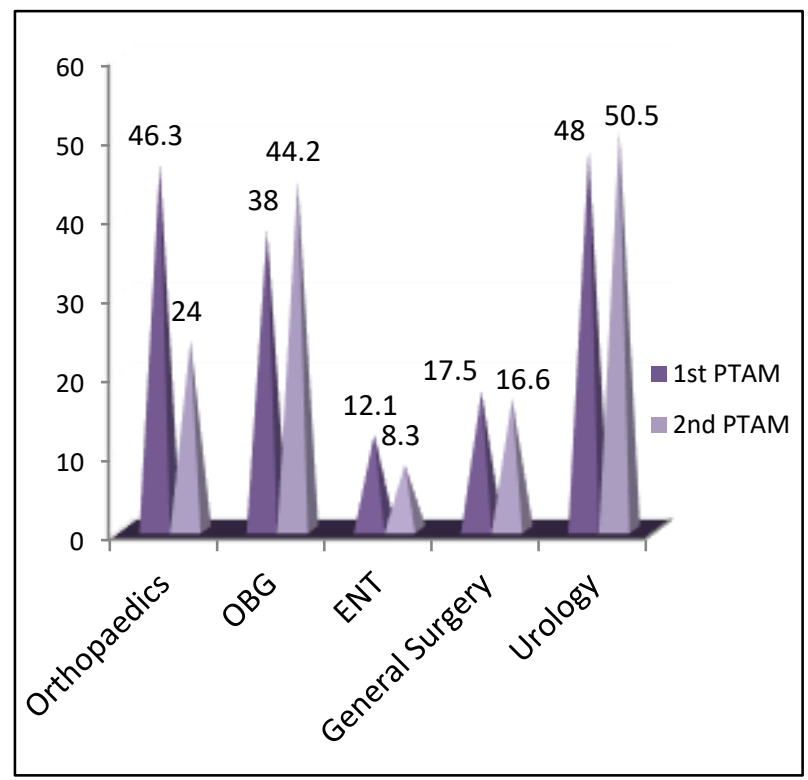

Figure 2: Percentage of drugs prescribed by generic names.

As far as the diagnosis and indication on prescriptions was concerned, a significant improvement was noted after a PTAM was held. An increment in documentation was seen in department of OBG $(p=0.59)$; ENT $(p=0.01)$ and urology $(p=0.06)$ (figure 3). Also, an improvement was noticed after PTAM in documentation of drug dosage in the departments of OBG $(\mathrm{p}=0.10)$ and general surgery $(\mathrm{p}=0.10)$. (Figure 4$)$
Documentation of drug frequency was seen to improve drastically after PTAM in the departments of OBG $(p=0.28)$ and ENT $(p=0.51)$, although it was not statistically significant. Similarly, regarding the documentation of duration of prescribed treatment, an improvement was noted in departments of orthopaedics $(\mathrm{p}=0.15)$, OBG $(\mathrm{p}=0.0015)$, ENT $(\mathrm{p}=0.90)$ and general surgery $(\mathrm{p}=0.002)$.

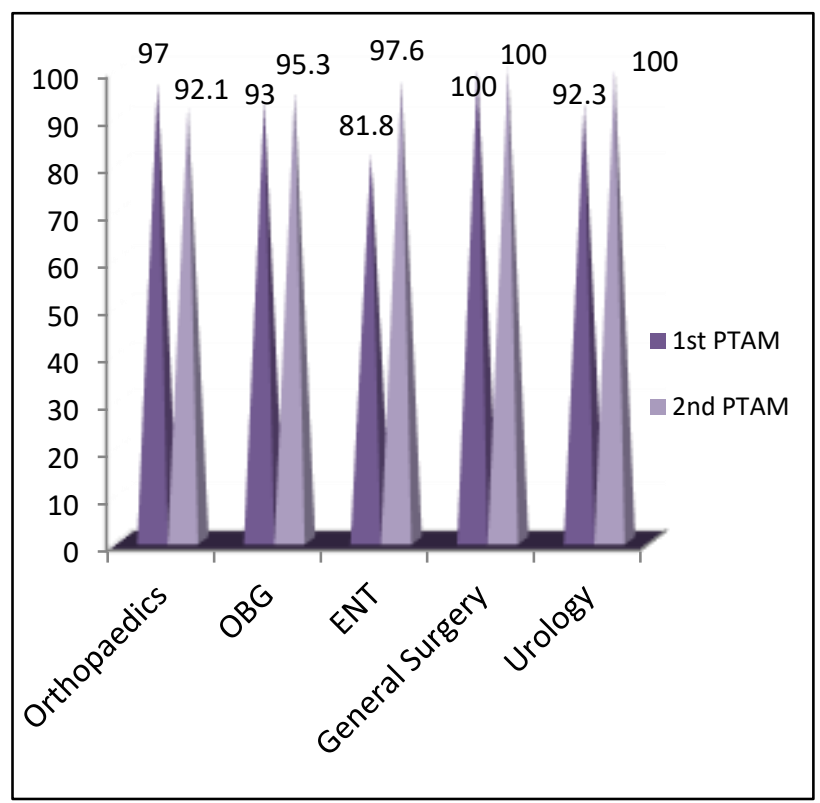

Figure 3: Percentage of prescriptions with diagnosis and indication mentioned.

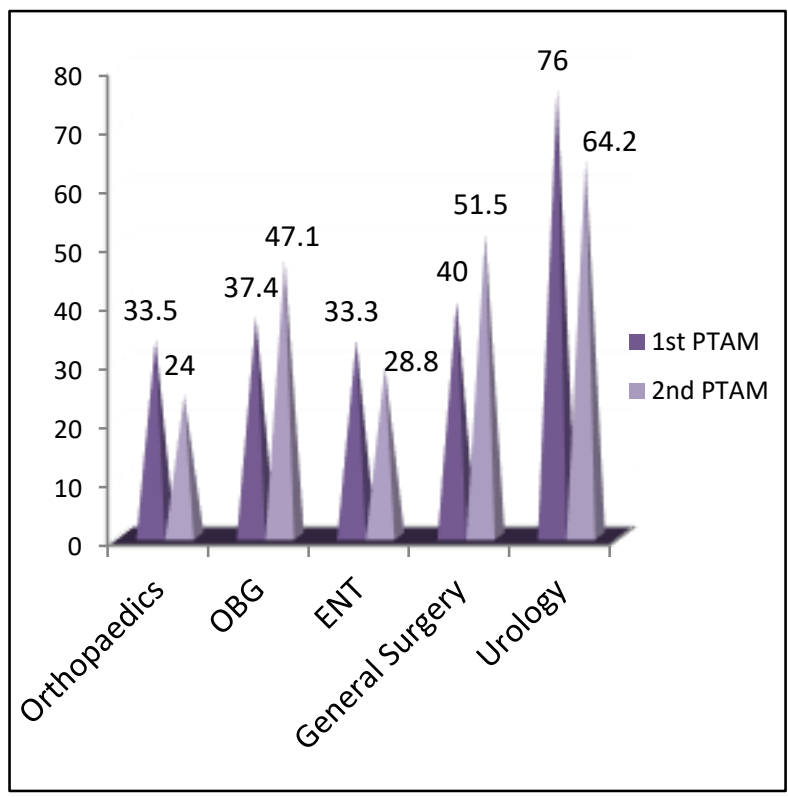

Figure 4: Percentage of prescriptions mentioning dosage of drug.

The prescriptions analysed in 1st PTAM and 2nd PTAM were scrutinized for number and class of antibiotic used. It was found that antibiotic was prescribed in $28.9 \%$ prescriptions in 1 st PTAM and $20.2 \%$ prescriptions in 2 nd 
PTAM. This decline was statistically significant $(\mathrm{p}=0.02)$. The overall rate of antibiotic prescription writing was $23.2 \%$. The most commonly prescribed class was beta lactam antibiotic followed by fluoroquinolones, macrolides, tetracyclines, urinary antiseptics, antifungals, oxazolidinone and aminoglycosides in decreasing order of their prescription usage. Also, a significant decline in antimicrobial prescription was observed in the department of obstetrics and gynaecology from $49.1 \%$ in prescriptions analysed for 1st PTAM to only $16.9 \%$ in prescriptions analysed for 2nd PTAM ( $\mathrm{p}=0.0002)$. A similar statistically significant decline was observed in department of ENT from $63.6 \%$ in 1 st PTAM to $32.1 \%$ in 2nd PTAM ( $\mathrm{p}=0.04)$. In department of general surgery this decline was noted, although it was not statistically significant. (Table1)

Table 1: Anti-microbials prescribed in 1st and 2nd PTAM

\begin{tabular}{|c|c|c|c|c|c|c|c|c|c|c|c|}
\hline \multirow[b]{2}{*}{ 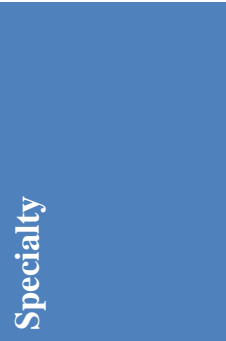 } & \multirow[b]{2}{*}{ 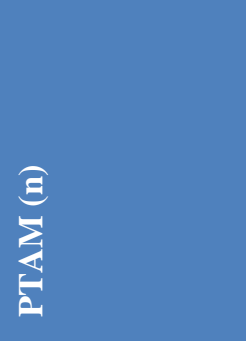 } & \multicolumn{7}{|c|}{ Antibiotics } & \multirow[b]{2}{*}{ 䮖 } & \multirow[b]{2}{*}{$\underset{\frac{\vec{E}}{\tilde{E}}}{\stackrel{0}{e}}$} & \multirow[b]{2}{*}{$\begin{array}{l}\stackrel{9}{E} \\
\stackrel{5}{2} \\
\varrho\end{array}$} \\
\hline & & 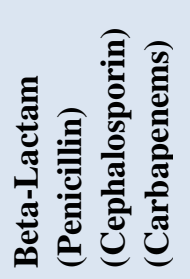 & 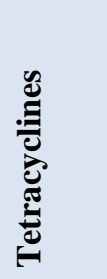 & $\frac{\substack{0 \\
0}}{\stackrel{0}{0}}$ & 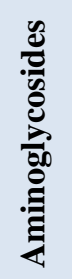 & 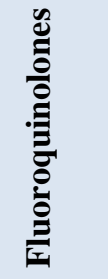 & 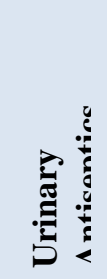 & 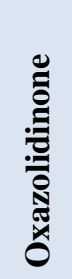 & & & \\
\hline \multirow[t]{2}{*}{ Orthopedics } & $1^{\text {st }}$ PTAM (66) & - & - & - & - & - & - & - & - & - & \multirow[t]{2}{*}{0.23} \\
\hline & $2^{\text {nd }}$ PTAM (89) & 2 & - & - & - & - & - & - & - & $2(2.2 \%)$ & \\
\hline \multirow[t]{2}{*}{ OBG } & 1 ${ }^{\text {st }}$ PTAM (57) & 12 & 6 & 2 & - & 3 & 2 & - & 3 & $28(49.1 \%)$ & \multirow[t]{2}{*}{0.0002} \\
\hline & $2^{\text {nd }}$ PTAM (65) & 1 & 1 & 1 & - & 3 & 3 & - & 2 & $11(16.9 \%)$ & \\
\hline \multirow[t]{2}{*}{ ENT } & $1^{\text {st }}$ PTAM (11) & 5 & - & - & - & 3 & - & - & - & $7(63.6 \%)$ & \multirow[t]{2}{*}{0.04} \\
\hline & $2^{\text {nd }}$ PTAM (84) & 14 & - & 1 & - & 11 & - & - & - & $27(32.1 \%)$ & \\
\hline \multirow{2}{*}{$\begin{array}{l}\text { General } \\
\text { Surgery }\end{array}$} & $1^{\text {st }}$ PTAM (33) & 10 & - & - & - & 3 & - & - & - & $13(39.4 \%)$ & \multirow[t]{2}{*}{0.16} \\
\hline & $2^{\text {nd }}$ PTAM (59) & 11 & & 2 & - & 1 & - & 1 & - & $15(25.4 \%)$ & \\
\hline \multirow[t]{2}{*}{ Urology } & $1^{\text {st }}$ PTAM (13) & - & - & - & - & 2 & 1 & - & - & $3(23.1 \%)$ & \multirow[t]{2}{*}{0.45} \\
\hline & $2^{\text {nd }}$ PTAM (44) & 7 & - & - & 1 & 4 & 2 & 1 & - & $15(34.1 \%)$ & \\
\hline \multirow{2}{*}{$\begin{array}{l}\text { Total and }(\%) \\
\text { Of antibiotics } \\
\text { PTAM-wise }\end{array}$} & $1^{\text {st }}$ PTAM (180) & $\begin{array}{l}27 \\
(52)\end{array}$ & $\begin{array}{c}6 \\
(11.5)\end{array}$ & $\begin{array}{c}2 \\
(3.8)\end{array}$ & - & $\begin{array}{c}11 \\
(21.2)\end{array}$ & $\begin{array}{c}3 \\
(5.8)\end{array}$ & - & $\begin{array}{c}3 \\
(5.8)\end{array}$ & $52(28.9 \%)$ & \multirow[t]{2}{*}{0.02} \\
\hline & $2^{\text {nd }}$ PTAM (341) & $\begin{array}{c}35 \\
(51)\end{array}$ & $\begin{array}{c}1 \\
(1.4)\end{array}$ & $\begin{array}{c}4 \\
(5.8)\end{array}$ & $\begin{array}{c}1 \\
(1.4)\end{array}$ & $\begin{array}{c}19 \\
(27.5)\end{array}$ & $\begin{array}{c}5 \\
(7.2)\end{array}$ & $\begin{array}{c}2 \\
(2.9)\end{array}$ & $\begin{array}{c}2 \\
(2.9)\end{array}$ & $69(20.2 \%)$ & \\
\hline \multicolumn{2}{|c|}{$\begin{array}{l}\text { Total antibiotics in } \\
\text { each class }(521)\end{array}$} & 62 & 7 & 6 & 1 & 30 & 8 & 2 & 5 & $121(23.2 \%)$ & \\
\hline
\end{tabular}

Table 2: Indices for various WHO core indicators.

\begin{tabular}{|lllllll|}
\hline Core Indicators & & $\begin{array}{l}\text { Antibiotic } \\
\text { prescribing }\end{array}$ & $\begin{array}{l}\text { Average No. } \\
\text { Of Drug }\end{array}$ & $\begin{array}{l}\text { Safety } \\
\text { injection }\end{array}$ & $\begin{array}{l}\text { Generic } \\
\text { name index }\end{array}$ & $\begin{array}{l}\text { Essential } \\
\text { medicine index }\end{array}$ \\
\hline Optimal Level & & $\leq 30 \%$ & $\leq 3$ & $\leq 10$ & $100 \%$ & $100 \%$ \\
\hline $\begin{array}{l}\text { Observed } \\
\text { Value }\end{array}$ & 1st PTAM & 28.9 & 2.2 & 1.5 & 36.1 & 63.7 \\
\hline INDEX & 2nd PTAM & 20.2 & 2.3 & 0.8 & 25.2 & 55.6 \\
& 1st PTAM & 1.03 & 1.3 & 6.6 & 0.36 & 0.63 \\
\hline
\end{tabular}

Index *Zhang and Zhi developed an index system to gauge the performance of a healthcare system in terms of drug utilization. For calculating average number of drug rational antibiotic and injection safety indices, the following formula will be used:

*Index=optimal value/observed value. All other indices (index of generic name, index of Essential Drugs List (EDL), consultation time index, dispensing time index, index of drugs actually dispensed, index of labelling of drugs, will be calculated by the following formula. *Index=observed value/optimal value 
Index system for drug utilization is important to gauge the performance of healthcare system, based WHO core indicators. A decline was observed in terms of antibiotic prescribing practice from $28.9 \%$ to $20.2 \%$ in 1 st and 2 nd PTAM respectively. A similar decline was noted in the use of injectable formulation from $1.5 \%$ in 1 st PTAM to $0.8 \%$ in 2nd PTAM. Also, the average number of drugs prescribed were in an optimal range (2.2 and 2.3 in 1st and 2nd PTAM respectively). (Table 2)

\section{DISCUSSION}

In this study, we screened and analysed the prescriptions from all surgical outpatient departments. All prescriptions collected were screened for rationality using WHO/INRUD core indicators by the investigator. Prescriptions with specific issues were reserved for discussion in PTAM. The purpose of PTAM was to review prescriptions for rationality and suggest measures for improving quality of prescriptions. Each drug written on prescription was individually screened for components of WHO/INRUD core indicators. PTAM was conducted after first screening and response to first PTAM was presented and discussed in second PTAM conducted afterwards. Effect of PTAM on writing prescriptions was visible on WHO/INRUD core indicators. Quality of prescriptions improved significantly in many parameters, while no improvement was seen in a few despite PTAM. In our study, we tried to improve prescription writing practices in our institute by PTAMs.

WHO reference values for prescribing indicators are $<2 \%$ for average number of medicines prescribed per patient encounter; $<20 \%$ for percentage of encounters with an injection prescribed; $<30 \%$ for percentage of encounters with an antibiotic prescribed; and $100 \%$ each for percentage of medicines prescribed by generic name and percentage of medicines prescribed from an EML or formulary. 5,6

In our study, the prescriptions were complete in terms of patient's name, age, weight, address, attending physician and date, as it was computer generated. As our institute is using e-hospital application for managing data, thereby omitting the possibility of flaws at superscript level to a greater extent.

As far as documentation of patient's disease diagnosis was concerned, we observed that in our study $95 \%$ prescriptions analysed in 1st PTAM and $96.4 \%$ of prescriptions in 2nd PTAM were complete in this aspect. This was quite higher than previous studies done by Saha et al, Mishra et al and Sandip et al with 40\%, 70\%, and $47 \%$ rates respectively. ${ }^{7,8,9}$ This marked difference could be probably due to better diagnostic facilities at tertiary care center with good laboratory support, which could have helped in establishing diagnosis prior to initiating treatment.
When the dosage prescribed in Outpatient department (OPD) slips was analysed, we observed that only $38.3 \%$ prescriptions in 1st PTAM had documented it, which improved to $41.8 \%$ in prescriptions analysed for 2 nd PTAM. This was in discordance with a study done by Raman et al and Ahsan et al with $83.5 \%$ and $76 \%$ documentation rates respectively. ${ }^{10,11}$ Use of fixed-dose combination leads to omission in writing doses in prescriptions.

Each treatment is given for a fixed number of days and it is quite important to mention the duration of therapy in each prescription. In many instances, it is seen that the patient takes a medication without a doctor's prescription resulting in erratic intake of a drug. In our study, we found that $58.9 \%$ prescriptions in 1st PTAM documented duration of treatment which drastically improved to $73.3 \%$ in prescriptions analysed for 2nd PTAM. Our study had much better result when compared to study done by Mishra et al with $27.5 \%$ prescriptions documenting duration of treatment. ${ }^{8}$ Our subsequent PTAM showed improvement in prescriptions in this aspect, hence proved beneficial.

Similarly, the frequency of drug in take is also an essential component of a prescription. In our study, we found that in prescriptions analysed for 1st and 2nd PTAM, 92.5\% and $92.4 \%$ prescriptions had documented frequency of drug intake. Very few studies were found to study this parameter of prescription. In a study by Sandip et al, a total of 427 prescriptions from department of medicine and surgery were analysed over a period of 8 months, showing a slightly higher rate $(14.2 \%)$ of omitting to write frequency of drug intake. Our study showed better result in this parameter. ${ }^{9}$

In our study, we found that $36.1 \%$ drugs were written by their generic names in prescriptions analysed for $1 \mathrm{st}$ PTAM, while it was lower $(25.2 \%)$ in prescriptions analysed for 2nd PTAM. In some studies, the rate of generic name writing was much higher, as in study done by Darji et al and Rishi et al with $63.3 \%$, and $51 \%$ rates respectively. ${ }^{12,13}$ While, in other studies, the rate of prescribing by generic names was much lower than our study, as seen in Ahsan et al, Aravamuthan et al, Mishra et al, Abidi et al with $0 \%, 2.5 \%, 3.7 \%$ and $3.7 \%$ respectively. ${ }^{8,11,14,15}$ As discussed in PTAMs, low rate of writing generic names was due to concern of physicians about the quality of drugs from different brands. Physicians were not convinced that quality of drugs is same across different manufacturers despite these agents being approved by drug regulatory body. In both the meetings, during discussion with administrators, it was highlighted by physicians, that they do trust a couple of brands to be of better quality than others.

An essential drug list framed by the government of India, includes those medicines that satisfy health care needs of population and should be available in adequate amount at all times. Our hospital did not have EDL at the time of 1st PTAM and need of local EDL was felt. It was decided to 
follow NELM 2015 till local list was framed. In our study, $63.7 \%$ prescriptions had drugs written from EDL in 1st PTAM, which declined minimally to $55.6 \%$ in prescriptions analysed for 2nd PTAM. In some other studies done by Ahsan et al and Darji et al, a rate of $79 \%$ and $73 \%$ was seen respectively which was much higher than our study results. ${ }^{11,12}$ This gross difference was probably due to the fact, that EDL is prepared keeping in view that major illnesses of patients can be managed with an affordable cost drug. At tertiary care center, we are dealing with super-specialty clinics, with advanced diseases and newer drugs as per updated guidelines. Additionally, lack of awareness among practicing clinicians, inability of some staff to participate in the audit meetings, recruitment of new staff, residents and faculty members and following some ongoing prescription writing practices could also have contributed to this finding. EDL was circulated to all concerned for modification of prescribing practice. This demands further PTAMs at regular intervals for execution of the knowledge instilled to the practitioners and residents.

In our study, the percentage of prescriptions containing antibiotics was calculated, and was found to be $28.9 \%$ in $1^{\text {st }}$ PTAM which improved further to $20.2 \%$ in 2nd PTAM. This rational use of antibiotics was a good practice in our center because of the clinicians' awareness. Also, our institute is conducting academic activities under "Antibiotic stewardship programme" at regular basis which aims to decrease undue antibiotic prescription writing. Our study showed best results in 2nd PTAM when compared with other studies done in the past. Darji et al, Ahsan et al, Aravamuthan et al showed a rate of $21.1 \%$, $39 \%$ and $22 \%$ respectively. ${ }^{11,12,14}$ It was interesting to note that beta-lactam class of antibiotics was prescribed the most. This is in agreement with National treatment guidelines for antimicrobial use in infectious diseases 2016 issued by National centre for disease control, India. ${ }^{16}$

An ideal prescription must contain minimal number of injectable formulation and must be avoided unless an alternative dosage form is available. In our study, we observed an improvement in injectable prescription writing from $1.5 \%$ in 1 st PTAM to $0.8 \%$ in 2nd PTAM. This result was in concordance with a study done by Sahaet al with a rate of $1.1 \% .{ }^{8}$ Some other studies done by Darji et al, Ahsan et al, Aravamuthan et al, Mishra et al the rates of injectable form usage were $29 \%, 7.5 \%, 7.2 \%$ and $6.1 \%$ respectively. ${ }^{8,11,12,14}$

Thus, PTAM proved to be an effective means of improving quality of prescriptions and introducing rationality in patient management in majority of parameters like documentation of diagnosis $(95 \%, 96 \%)$, dosage $(38.3 \%$, $41.8 \%)$, duration $(58.9 \%, 73.3 \%)$, injectable formulation $(1.5 \%, 0.8 \%)$ and antibiotic prescription $(28.9 \%, 20.1 \%)$ for both PTAMs respectively. The results were promising by the use of PTAM as an intervention. PTAM could be effective on another tier of health care system, thereby heading towards good clinical practice and improved patient care.

\section{CONCLUSION}

There was a significant improvement in quality of prescriptions in terms of documentation of disease diagnosis, dosage, frequency, duration and generic names. Moreover, there was also an improvement in rational antibiotic prescribing which showed the potential of PTAM as intervention to effectively improve antimicrobial prescribing. Improved quality of prescription was evident from limited use of injectable formulations in the study. Our research showed PTAM could be effective tool to implement WHO/INRUD drug prescribing indicators robustly.

\section{Funding: No funding sources \\ Conflict of interest: None declared \\ Ethical approval: The study was approved by the Institutional Ethics Committee}

\section{REFERENCES}

1. Hogerzeil HV. Promoting rational prescribing: an international perspective. $\mathrm{Br} \mathrm{J}$ Clin Pharmacol. 1995;39:1-6.

2. Proceedings of the twentieth anniversary symposium. ATC/DDD classification. WHO Collaborating Centre for Drug Statistics Methodology. WHO Drug Information. 2002;16:3.

3. Nuthan KUS, Nalini GK, Deepak P, Prema M, Rathod G, Mohith N. Prescription audit of outpatients in tertiary care government hospital. Int J Basic Clin Pharmacol. 2018;7(4):636-9.

4. El Mahalli AA. WHO/INRUD drug prescribing indicators at primary healthcare centers in eastern Province, Saudi Arabia Eastern Mediterr Health J. 2012;18(11):1091-6.

5. Harvard Medical School and Harvard Pilgrim Health.Using indicators to measure country pharmaceutical situations. Fact Book on WHO Level I and Level II monitoring indicators. Geneva: World Health Organization; 2006. Available at: https://www.who.int/medicines/publications/WHOT CM2006.2A.pdf Last accessed on 20 June 2020.

6. Dumoulin J, Kaddar M, Velasquez G. Guide to drug financing mechanisms. Geneva: World Health Organization; 1998. Last accessed on 20 June 2020.

7. Saha A, Bhattacharjya H, Sengupta B, Debbarma R. Prescription audit in outpatient department of a teaching hospital of North East India. Int J Res Med Sci. 2018; 6(4):1241-7.

8. Mishra S and Sharma P. Prescription audit and drug utilization pattern in a tertiary care teaching hospital in Bhopal. Int J Basic Clin Pharmacol. 2016;5(5):18459.

9. Patel S, Patel A, Patel V, Solanki M. Study of medication error in hospitalised patients in tertiary care hospital. IJOPP. 2018;11(1):32-6. 
10. Raman V, Sakthi G, Guru R, Ravikumar T, Manjula M, Poongodi P et al. Prescription audit in outpatient departments in tertiary care hospitals -a prospective study. Indian J Basic Appl Med Res. 2018;7(4):354-8.

11. Ahsan M, Shaifali I, Mallick AK, Singh HK, Verma S, Shekhar A. Prescription auditing based on World Health Organization (WHO) prescribing indicators in a teaching hospital in North India. Int J Med Res Rev. 2016;4(10):1847-52.

12. Darji NH, Vaniya HV, Doshi CM, Hedamba RH, Jadav SP, Trivedi HR. Prescription audit in the inpatients of a tertiary care hospital attached with medical college. J Clin Exp Res. 2015;3(2):197-200.

13. Rishi RK, Sangeeta S, Surendra K, Tailang M. Prescription Audit: Experience in Garhwal (Uttaranchal), India. Tropical Doctor. 2003; 33(2):769.

14. Aravamuthan A, Arputhavanan M, Subramaniam K. Assessment of current prescribing practices using World Health Organization core drug use and complementary indicators in selected rural community pharmacies in Southern India. J Pharm Policy Pract. 2017;10(1):1.

15. Abidi A, Gupta S, Kansal S, Ramgopal R. Prescription auditing and drug utilization pattern in a tertiary care teaching hospital of western UP. Int J Basic Clin Pharmacol. 2012;1(3):184-90.

16. Directorate General of Health Services Ministry of Health \& Family Welfare Government of India; National Centre for Disease Control; Version 1.0. 2016. www.pbhealth.gov.in/amr_guideline. Last accessed 20 June 2020 .

Cite this article as: Kumar V, Kant R, Handu S, Charturvedi J, Bhadoria AS, Dhamija P.

Pharmacotherapeutic audit meetings as a tool of improving prescribing practices. Int J Basic Clin Pharmacol 2020;9:1587-93. 